\title{
Accounting Career Choice Theories: Is Culture an Impediment?
}

\section{Ali Rkein}

Charles Darwin University

Accounting Department

\author{
Hassan Ibrahim Rkein \\ Faculty of Business Administration, Accounting Department, \\ Al Maaref University, Beirut, Lebanon
}

\begin{abstract}
At a time where an enormous amount of resources have been allocated and spent towards achieving a promising future for all Australians including aboriginal and Torres Strait Islander people. And In a period of increasing awareness among Indigenous Australians that accounting specialization is important and greatly needed for self-determination, the inferior representation of Indigenous Australians majoring in accounting requires attention to understand the reasons behind the dearth of Indigenous accountants that exist in the profession. This paper, while drawing on career choice theories, builds on the Yin/Yang principles of societal values of life, developed by Hines (1992), to explain the cultural constructs of developing an intention to major or not in accounting. The paper tries to identify the impediments preventing Indigenous students from majoring in accounting, by understanding the Yin-based Indigenous cultural identity and relating it to the Yang- infused accounting values.
\end{abstract}

Keywords: Accounting, Career Theory, Indigenous, Culture, Outcome Expectation, SelfEfficacy

\section{INTRODUCTION}

The dramatic decline in the number of students majoring in accounting over the last decade has raised serious concerns amongst accounting professional bodies about the status of accounting education (Hardin et al., 2000; Jackling and Calero, 2006; Sherman and Tymon, 1997; Albrecht and Sack, 2000). Although the decline has been common to many developed countries, the inferior representation of Indigenous students studying accounting in Australia has triggered additional attention and an anxious interest amongst universities and researchers to know the reasons pertinent to this ethnic group of people. Despite governmental efforts and initiatives to promote majoring in accounting by providing scholarship assistance to students and subsidies to universities and training organizations for recruiting Indigenous students, the number has remained low, with an estimate of only ten (10) Indigenous accountants among the 180,000 Australian professional accountants (Lombardi and Clayton, 2006; Rose, 2012).

Indigenous leaders and over last few years have been highlighting and greatly acknowledging this inferior representation in accountancy. For many years, careers such as law, teaching and nursing have been valuable to Indigenous people but accounting as a career choice was not seen as equally valuable or needed. However, recently, an increasing awareness has been spreading in the Indigenous community regarding the value that accounting offers in seeking self-determination and impartiality in administering the community affairs, and in sharing the control over the community and the nations' wealth. In this sense, understanding the reasons why Indigenous students do not major in accounting becomes quite important and necessary in the quest to increase the number of Indigenous accounting students. This study discusses 
different constructs that drive a particular career choice from a cultural perspective in a way that aims to reveal that the Indigenous cultural values of life contradict with the Western, capitalist values implicit in the accounting career.

A review of the literature on career choices among students and minority ethnic groups is presented in the next section. It is then followed by a section which discusses the theoretical model of the study that draws on different career choice theories used in previous studies, and on the "yin and yang" values framework of Hines (1992) to examine the cultural values of life and the constructs of a career choice. The third section analyses the two constructs of a career choice, self-efficacy and outcome expectations, from an Indigenous cultural perspective. The section discusses how these constructs conflict between Indigenous cultural values and accounting as a career. Finally, the study concludes with a summary and conclusion.

\section{LITERATURE REVIEW}

Given the dearth of research surrounding Indigenous education in general and accounting education in particular, it was necessary in this section to present three categories of the literature that have been reviewed to inform the study and develop the theoretical framework. The first category is the career choice literature that addresses the different reasons and factors for choosing a particular career. The second category is the accounting education literature that discusses the different reasons behind majoring or not majoring in accounting. The third category is the literature on Indigenous Australians' education and culture history.

Many studies have pointed out that a student's intention to major in a particular field is affected by factors such as self-efficacy, working conditions, social values, and some other stereotypical personal characteristics (Hermanson and Hermanson, 1995; Horowitz and Riley, 1990; Garner and Dombrowsky, 1997; Gul, 1986; Wolk and Cates, 1994). These studies have generally used diverse career choice theories, such as the theory of reasoned action (Fishbein and Ajzen, 1975), the theory of planned behaviour (Ajzen, 1988), and the social cognitive career theory (Gainor and Lent, 1998) to explain factors that drive a particular career choice. For example, Gainor and Lent (1998) used the social cognitive career theory in predicting math choice intentions for African American students. Lent, Brown and Sheu (2005) used the same theory in an engineering context.

On the other hand, prior research has addressed students' studies of accounting in general (Albrecht and Sack, 2000; Birrell et al, 2005; Booth and Winzar, 1993; Boughen, 1994; Cohen and Hanno, 1993; Gul, 1986; Hardin et al, 2000; Inman et al, 1989; Jackling and Calero, 2006; James, 2008; Mladenovic, 2000; Parker, 2000; Parker, 2001; Sherman and Tymon, 1997; Smith, 2005; Albrecht and Sack, 2000; Zeff, 1989; Wolk and Cates, 1994). These studies have found different contributing factors to majoring or not majoring in accounting and discussed them from different perspectives. Some of these studies have examined the personal and intrinsic factors between students, by analyzing their perception and attitudes towards accounting (Albrecht and Sack, 2000; Booth and Winzar, 1993; Boughen, 1994; Gul, 1986; Jackling and Calero, 2006; Lippmann, 1992; Wolk and Cates, 1994). In some of these studies (Adams et al., 1994; Auyeung and Sands, 1997; Lowe and Simons, 1997; Paolillo and Estes, 1982) it was found that factors related to the availability of employment and earnings are important in the students' choice. Other factors include perceived job satisfaction, aptitude, and interest in subject areas were also found (Auyeung and Sands, 1997; Gul et al., 1989; Paolillo and Estes, 1982). Also, unfavorable perception of accounting has been recorded and many students have been found to perceive accounting as quantitative and boring (Cohen and Hanno, 1993; Jackling and Calero, 2006; Mauldin et al, 2000; Mladenovic, 2000; Parker, 2000; Parker, 2001). The influence of teachers, friends, families and media has also been suggested as factors which 
influence majoring in accounting (Brown, 1996; Cangelosi et al., 1985; Geiger and Ogilby, 2000; Gul et al., 1989; Paolillo and Estes, 1982; Roe and Ester, 1999). Furthermore, some studies have studied the relation between students' social values and majoring in accounting. Brown (2002) and Simpson (2001) have found that where collective social values are highly appreciated, the career choice will be rather consistent with the group and community values than individual values.

Reviewing the above literature has assisted in considering the possible impediments and barriers for studying accounting. Self-efficacy as represented by the educational level, literacy and numeracy for Indigenous students, in addition to their cultural values and work expectations were chosen to be examined in order to study the negative representation of Indigenous students in accounting. Hence, it became necessary to review some of the historical literature on Indigenous education and culture (Blake, 1981; Gibson, 2000; Godfrey et al, 2001; Harris, 1987; Harris, 2000; Lovesy and Fraser, 1999; Watson et al, 2006; etc...).

\section{THEORETICAL FRAMEWORK}

The theoretical framework for this study draws on different theories that were used in the literature to explain the intention for a particular behaviour, and more specifically in accounting research to explain factors affecting career choices. These theories are the theory of reasoned action (TRA) developed by Fishbein and Ajzen (1975), the theory of planned behaviour (TPB) (Ajzen, 1988), and the social cognitive career theory (Gainor and Lent, 1998). The theory of reasoned action conceives intention to be determined by the 'individual's attitude' towards a particular behaviour and it is subject to the influence of some 'referents' (parents, instructors, friends, etc.). The individual's attitude is determined by the individual's beliefs about the outcomes and consequences of a particular behaviour, and the influence by referents represents the social environmental pressure to perform or not to perform the behaviour.

The social cognitive career theory, added an additional personal variable, 'self-efficacy', to the 'individual's attitude' variable to explain that intention for a behaviour is also determined by the persons' perception of their aptitude to perform career-related activities. As some factors may interfere with an individual's intention towards a particular behaviour (Cohen and Hanno, 1993, p. 222), the theory of planned behaviour was more explicit in incorporating an additional pro/anti control factor, which represents either an additional incentive to perform the behaviour in line with the individual attitudes (pro), or a prohibitory factor to not perform the behaviour in contrast with the individual attitudes (anti) (Ajzen and Madden, 1986; Ajzen, 1988).

While many studies have used these theories to explain and explore factors affecting students' intentions to major in a particular discipline or in accounting, cultural factors did not receive explicit consideration and were only recognized implicitly as part of the social and environmental factors identified. These studies have recognized culture as a pro/anti control factor that may influence, subsequently, the intention to the behaviour that had been developed already from the individual's attitudes and outcome expectations of a particular career. However, the differentiation of this study is in its consideration of culture as a system in which 'individual's attitudes' and 'outcome expectations' are profoundly embedded within cultural values and they develop in line with the structural elements of this culture (Greer and Patel, 2000; Hofstede, 1980, 1983). Hofstede (1980, p.25) defined culture as "the collective programming of the mind which distinguishes the members of one human group from another". Thus, culture is a system of societal values where values are "a broad tendency to 
prefer certain states of affairs over others" (Greer and Patel, 2000; Hofstede, 1980, p. 19). Hence, this study recognizes culture as an essential element for understanding how individuals' attitudes and outcomes expectations are shaped and defined by the norms and values of a particular ethnic group, in a way that may result in a common response to a particular career choice. Hines (1992, p.318) explained that the structural elements of culture are depicted by "the universal masculine or yang and the feminine or yin" conceptions. A masculine culture exists when the society prefers individual independence, competition, ambition, wealth, and material success. On the contrary, a feminine culture exists when the society prefers common goals, relationships, modesty, and the quality of life (Hofstede, 1980). Hence, in identifying the factors that deter Indigenous students in Australia from majoring in accounting, this study considers the structural elements of the Indigenous culture in terms of its masculinity or femininity and relates them with accounting work values.

In this regard, and as proven by many studies, there is no doubt that students who choose accounting believe it is a career that provides them with high income, long term career advancement, prestige and social status, personal growth and development, a good work environment, and the opportunity for leadership and proprietorship (Felton et al., 1994; Hermanson and Hermanson, 1995; Inman et al., 1989; Lowe and Simons, 1997; Lancaster University, 2009; Paolillo and Estes, 1982; etc.). This means that these perceived benefits correspond with the masculine work value dimension of culture. On the other hand, the literature reveals that Indigenous Australians' cultural values are aligned with the feminine dimension of cultural values (Bell, 1986; Berndt and Berndt, 1988; Cohen and Somerville, 1990; Elkin, 1981; Harris, P., 1991; Keeffe, 1992; Peterson and Langton, 1983; Povinelli, 1993, etc). Hence, it is important to examine whether students from an ethnic society, which is characterized by feminine characteristics of culture, such as the Indigenous Australian communities, are unlikely to choose a major such as accounting that is driven by a masculine dimension of work values.

Informed by the above theories, the study draws on both primary and secondary data. Primary data was collected by conducting semi-structured interviews with indigenous students, teachers, principals, career advisors in Indigenous communities' schools and in boarding schools (outside the community), and with a focus group of students' parents. Secondary data was collected from government reports and the extant literature on Indigenous Australians.

\section{SELF-EFFICACY}

Self-efficacy refers to the individual's beliefs about his or her ability to carry out the activities pertinent to a particular career. The theoretical framework in this study conceives that students would develop an interest to major in accounting if they consider themselves competent in the necessary skills, and they would not develop an interest if they see themselves as incompetent. While there have been some studies that used self-efficacy in explaining the state of representation for some ethnic groups in some occupations (Gaffney et al., 1995; Gecas and Schwalbe, 1983; Hughes and Demo, 1989; Witherspoon and Speight, 2009), there has been no research that directly examined the self-efficacy of Australian Indigenous students in accounting. However, several studies have actually shown a widespread perception of accounting as being numbers-based (Cohen and Hanno, 1993; Jackling and Calero, 2006; Mladenovic, 2000; Parker, 2000, 2001) with an adequate language proficiency requirement (Grace and Gilsdorf, 2004; Wallace, 1997; Wong and Chia, 1996). Subsequently, in this study, the self-efficacy for Indigenous students is considered to be reflected by the numeracy and literacy skills required to perceive themselves capable of majoring in accounting. Therefore, this study discusses the self-efficacy for Indigenous students by discussing its two constructs: numeracy and literacy. However, as these two 
constructs are shaped by the institutional environment in which they develop and form, discussing the educational system as the broader construct would also be useful and informative.

\section{EDUCATIONAL SYSTEM EFFICACY}

Studying the broader construct of the educational system efficacy may prove to be informative in this study in the sense that it has some implications for student's self-efficacy in accounting. Hence, it is proposed in this study that a low educational system efficacy may result in a low self-efficacy for Indigenous students to the extent where the minimum efficacy, perceived necessary to pursue accounting, is not attained.

The general school educational system for Indigenous students has been heavily westernculture based with a lack of consideration of their needs in terms of cultural values, norms, language, and social belonging. The disaffection of students and parents, added to living in a disadvantaged socio-economic environment characterized by poverty and high levels of sickness, results in a high level of absenteeism and truancy and an overall underrepresentation in school education (Godfrey et al., 2001; Harris, 2000; Helme, 2005; McMillan and Western, 2000).

The disadvantaged socio-economic environment has made it difficult for Indigenous families to assume their basic needs of food, shelter and security, and made it inconvenient for many students to feed, dress and get to school without the support of their parents. This has resulted in a poor attendance at primary school levels and only a few students reaching the upper years of schooling. In the year 2009, the student survival rate to the final year of school has been about $45 \%$ of Indigenous students in comparison with $76 \%$ of non-Indigenous students (Helme and Lamb, 2011). A school teacher commented in this regard by saying that: "Indigenous students do not have the consistency of learning everyday one step on top of the other, because they are not used to going to school daily and their parents do not force them to. This results in very broken interrupted school learning". (Table 1 shows secondary school attendance, for year 2006, for ages 15 to 17 between Indigenous and non-Indigenous students). In addition, cultural ceremonies and rituals have interrupted students' primary years of education and their consistency of learning. For example, "in the case of death in a community, the whole class might shut and some families may have to go to another community for a week or more" according to an Indigenous school teacher.

Table 1: (Secondary School Attendance by Age in 2006)

\begin{tabular}{|c|c|c|}
\hline Age & $\begin{array}{c}\text { Indigenous } \\
\text { \%age }\end{array}$ & $\begin{array}{c}\text { Non-Indigenous } \\
\text { \%age }\end{array}$ \\
\hline 15 & 73 & 89 \\
\hline 16 & 55 & 81 \\
\hline 17 & 36 & 66 \\
\hline
\end{tabular}

(Source: Australian Bureau of Statistics, 2006)

These factors which result in poor attendance and high levels of absenteeism have made some concerned families, who are more dedicated to their children's learning, to send them outside their communities to boarding schools which also teach non-Indigenous students. Although this has improved class attendance for these students, only a few of them are able to adjust to 
the new environment and make it through to graduation. The majority of students find it difficult to be disciplined and to obey school rules. Some students, for example, have cited wearing shoes as an issue for them. Also, many of them become homesick and fail to return to school after their holidays. This is reflected in the decreasing figures of secondary school attendance reported in Table 1 . A boarding school principal stated that "... when they board here, they feel homesick, particularly if they are not sent with a large group of their peers. Having one or two from one community is hard as they will be extremely lonely here, no one knows their background or sometimes speaks their language, and therefore, they will decide to go home". Another boarding school principal added that "many students do not return to the school after their break holidays because they could not cope with being away from home and because they are not ready for the rules and the discipline, such as wearing shoes every day, school uniforms, getting up at six, having breakfast, cleaning the room, making the bed and being in class on time. They found these very difficult and repetitive".

In addition, the deprived quality of education in primary schools in communities resulting from poor attendance has made these students arrive to boarding schools poorly prepared to continue their education. Indigenous communities do not follow mainstream curricula, they have inadequate space, and lack sufficient teaching materials. The students are, in addition to their poor literacy and numeracy, frequently underprepared for the use of technology such as computers and calculators (Commonwealth Department of Education, Training and Youth Affairs, 2000; Hunter, 2010; Purdie and Buckley, 2010; Reid, 2008). This situation has led many boarding schools to segregate Indigenous students from non-Indigenous students because of the difference in their education levels. While such segregation does not encourage biculturalism and condemns these students to loneliness, it also results in accounting as a school course not being offered to this stream of Indigenous students according to boarding school teachers interviewed.

"... their literacy and numeracy is not the same as other students, it is actually very bad. If you can't read and write English to a certain standard, and if they do not have the basics of western numeracy because it is not in their culture to count in tens and hundreds and thousands, so if they do not have these basic stuff, then it is going to be very difficult for them to pass accounting classes".

Another boarding school teacher similarly commented: "community students have lost a lot of school days because of culture ceremonies. The absence of continuity in education has vanished them a lot of their basics. Therefore when community students come to here, there is a lot of back tracking to catch them up to speed, they are always behind with everything, and some of the subjects are too difficult for them, accounting will be one of those difficult subjects".

And another confirmed that "it is unlikely for Indigenous students to venture into choosing to enroll in what they call hard subjects such as accounting".

Hence, cultural values, norms and rituals, and social belonging have resulted in a lack of emphasis on formal education which leaves Indigenous students inconsistent in their school attendance and unable to attain the competency to be placed in a stream of classes where they would be given the opportunity to study accounting in their secondary years of education. This has deprived them of the opportunity to learn about accounting and to develop a particular understanding of its concepts and its outcome expectations which may result in an intention to major in it. 


\section{Numeracy}

A number of studies have examined the relation between students' perception of accounting and its influence on majoring in accounting. Many of these studies have found that there is a common perception that accounting is numbers-based associated with an emphasis on numerical accuracy, routine recording and calculation, and attention to details, and that a student must be good with numbers to major in accounting (Cohen and Hanno, 1993; Jackling and Calero, 2006; Mladenovic, 2000; Parker, 2000; Parker, 2001; Smith, 2005). In the US, an initiative to increase the number of students majoring in accounting has focused on launching and sustaining contact with school mathematics teachers (Smith, 2005).

It is suggested by the literature that students who lack these numbers-related skills (mathematics) are unlikely to develop an intention to major in accounting. In this regard, a recent study by Watson et al., (2006) has shown that Indigenous students' average performance in mathematics is under State and National averages at all school levels. A good performance in mathematics is considered to be culturally inclusive, in the sense that it requires excellent supportive teachers and a strongly supportive learning environment (Watson, 2006). Drawing on the discussion in the previous section, it seems clear that such a supportive learning environment is not available to many Indigenous students. In addition, the review of Indigenous Australian literature shows that their counting systems or more generally their mathematical concepts do not go very far in comparison with western-based mathematical concepts. Previous research on Indigenous number skills and counting system indicated that such a system is poor and it lacks the structure to be called a system in the first place (Brandenstein, 1970; Harris, 1987). Blake (1981) claimed that Australian Indigenous not only did not develop mathematics, "but did not even feel the need to count" (Blake 1981, p.3). The Statements of Indigenous Australians counting systems did not go beyond four (Blake, 1981). Some authors argued that the absence of numbers beyond four does not necessarily reflect an inability for counting beyond that number. Harris (1987), Haddon (1890), and Tindale (1925) reported real examples of some Indigenous people being able to communicate information on numbers beyond four although no specific terms were used.

While Harris (1995) and others have rejected the statement that the inability of Indigenous Australians to count is due to the absence of counting words, they have all acknowledged that language is reciprocal to numeracy, in the sense that a concept cannot be understood if there isn't a word for it (Lovesy and Fraser, 1999). Hence, the absence of many numerical concepts from the Indigenous culture (such as over, above, higher, greater than, more, up, bigger, larger, under, below, lower, beneath, less than, down, smaller), have made it difficult for students to understand these concepts when they are discussed in mathematical classes (Watson et al., 2006) and hence in accounting classes. The Indigenous culture has been less concerned with quantity and accuracy measures, so that it is unlikely that these terms would be easily understood by them.

The limited numeracy skills and the lack of understanding of most of the quantitative measures have made Indigenous students struggle in mathematical classes and in accounting courses at school levels. This has, over time, created among them a perception that accounting is difficult and it requires a strong mathematical competency.

\section{Literacy and Culture}

Language is considered an essential construct in developing a sufficient efficacy for majoring in accounting. Several studies have shown that a proficiency in English as the national language is critical to performing well in accountancy and to students in developing a favourable intention 
of majoring in accounting. However, the review of Indigenous Australians literature and the accounting language in its current western-base has revealed that they do not share the same language and terminology. It is even suggested that some accounting terminology may have a contrasting meaning within the feminine values of Indigenous culture. Hence, it is suggested in this study that a lack of common terminology or mutual understanding between a westernbased accounting language and the Indigenous language may impede Indigenous students' understanding of accounting terms to the extent that they would become discouraged from majoring in accounting.

The meaning of western-based accounting language and terminology is generally rooted within notions of economic growth, wealth, competition, assets, and financial rewards. Such notions lack meaning in a society whose need for food, shelter, and spiritual enrichment are all provided by the land, and to whom the wealth is wisdom, kinship, sharing, and cooperation. Hence, it is anticipated that Indigenous students face difficulties in developing a clear, noncontrasting understanding of accounting terminology to the extent that they become hesitant about majoring in accounting. A concept cannot be understood clearly if there isn't a word for it (Lovesy and Fraser, 1999), for example, the lack of words for expense, revenue, budget, cost, variance, and profit may necessarily prohibit an understanding of the use of these words. However, a greater difficulty would be experienced by students when they need to learn terms that have a conflicting meaning as per their language, for example, own, asset, and inventory, etc... 'To own', in Indigenous culture, means to have the obligation to share, or the right to be asked (Myers, 1976). Hence, an exclusive possession does not exist and it is substituted by caring and sharing. This is particularly evident in their notion of land where Dingle (1988, p.10) wrote: "land was used, cared for and held in trust for future generations. It was also shared with others: to control land is not to enjoy it exclusively but rather to exercise the right, which is at the same time an obligation, to allocate rights in its resource to others". Hence, the western notion of an asset in which what is owned is normally controllable conflict with the Indigenous kinship and social obligations that tend to consider the asset as a liability (Gibson, 2000), in the sense that it creates an obligation to share and to be asked.

The kinship system that is very dominant in Indigenous societies is very different to the system in non-Indigenous societies. The Indigenous individual is totally bound to other members of his or her society (Blake, 1981). On the other hand, the non-Indigenous individual treats others of their society as competitors.

An Indigenous student participating in this study stated that: "The teacher that I worked with made the job look so easy, but at the end it was pretty hard.' The student has now moved to the health profession because '... nursing seems a lot easier.'

There was a noticeable perception amongst the research participants of a strong relationship between accounting and mathematics. Many of the participants in this study declared that accounting is not an area of interest for them, and that their opinion is not critical of accounting. The reason for the lack of interest is that they are 'not good with maths and/or numbers'. For instance, a participant who is very certain that she will not do accounting. She said this is 'not because I do not like accounting, but more because I'm not good at maths; I'm not good at numbers'.

While in many instances low self-efficacy regarding mathematics has played a crucial role in keeping students away from accounting, a participant's high self-efficacy in English has played a significant role in her decision to become an English teacher. She stated that: 'Well, I really liked English, and I always scored high or maybe the highest sometimes.' 
Others also declared that the perception of accounting as a number crunching exercise is what affected their confidence about studying the subject. They stated that: 'When I think of accounting, I think of numbers, they (numbers) scare me. I do like maths, but was not good at it.' Another student stated that: 'You need to be so smart at maths, I am not. That is another reason why I have never thought about it.'

\section{Outcome Expectations}

Drawing on the theoretical framework for this study, an individual is likely to develop an intention towards a particular career if the outcome expectations of the career match his or her work values. James (2008) defined outcome expectations as the consequences of practicing a career, and work values as the work standards that the individual wants to live by. Brown (2002) considered that work values play an important role in identifying an individual's career goals. Hence, this section discusses whether the Indigenous students' work values match or mismatch the outcome expectations associated with majoring in accounting.

Accounting is considered to be at the heart of the liberal ideology on which the capitalist economic system is based (Lombardi and Clayton, 2006). As a "constructed device for dealing systematically with commercial or financial aspects of the affairs of persons, firms and other organizations" (Chambers, 1991, p.3) accounting has emphasized and maintained the capitalist ideology of individualism, personal wealth creation, and ownership (Lombardi and Clayton, 2006). This means that working in accounting would furnish the individual with opportunities in: developing networks with professional and wealthy people; professional development into leadership positions; working in a professional flexible environment; and in a growing financial comfort. Studies have shown that accounting is perceived by students to be a career that provides high earnings potential, secure job market conditions, and opportunities for development and advancement (Adams et al., 1994; Ahmad et al., 1997; Auyeung and Sands, 1997; Felton et al., 1994; Gul et al., 1989; Inman et al., 1989; Lowe and Simons, 1997; Mauldin et al., 2000; Paolillo and Estes, 1982). A study at Lancaster University grouped students' perceived benefits of accounting into four categories: stimulation, reward, variety, and leadership (Lancaster University, 2009). The 'high class' capitalist world of business and money attracts and stimulates students to work in the elite corporate world, and accounting provides an ideal opportunity to gain access, especially after accounting has been placed at the top of the business agenda as a result of the recent financial scandals. Also, the study has shown that students perceived accounting as a rewarding career which offers a sustainable financial reward. In addition, accounting offers a variety of career choice that suit all interests including auditing, assurance, management, consulting, tax planning, human resource, etc... Finally, accounting was perceived to have a high prospect of promotion to leadership positions within organizations.

Building on the results of the study above and many other studies (Adams et al., 1994; Ahmad et al., 1997; Auyeung and Sands, 1997; Felton et al., 1994; Gul et al., 1989; Inman et al., 1989; Lowe and Simons, 1997; Mauldin et al., 2000; Paolillo and Estes, 1982), it can be said that students who intend to major in accounting have masculine work values, in the sense that they conceive financial prosperity, productivity, and independence should accompany one's work (James, 2008). Hence, accounting students find a match between their work values and the materialistic, capitalist outcome expectations of accounting.

However, work values for Indigenous students have been disconnected from the market, masculine, capitalist dimension and are more unified with their land values, in which employment does not have the same economic imperative as for non-Indigenous people (Greer 
and Patel, 2000). "Many (Indigenous) place no importance on continual employment, and work is generally regarded as an economic necessity, rather than as a part of a lifetime plan" (Eades, 1988, p. 99). The land for Indigenous people is kin. It is an intimate part of the life, culture, personality, religion, sovereignty, autonomy and self-determination. For them, land is not an "object-like to be manipulated, exploited and mastered" (Sharp, 1996, p. 137). Land is alive and spirited and from which they derive their identity (Maybury-Lewis, 1992), hence they are bound by duty and responsibility to protect it and preserve it for future generations. Thus the custodianship and the kin relationship with the land take preference over all economic matters. Therefore, the work values of Indigenous people lies in having an employment that contributes to maintaining relationships with the land and their communities. In this regard, Indigenous students interviewed in this study have all expressed preferences for careers that contribute to their communities.

"I want to be involved in the community, like everyone in my family"

"Being part of the community is what is important to me..."

"I want to be a teacher in remote communities because I want to be with my family and out bush"

"I do not see myself doing accounting; law would seem more to benefit my community in defending and protecting their rights"

A common theme that emerged from the interviews is a 'pull back' to the life in the community. Working in elite professional organizations at a desk with a computer in an air-conditioned office, wearing suits, and earning high salaries did not have much appeal to Indigenous students.

"I could work and earn 100 thousand dollars a year but that will not make me happy if I am away from my family and my community. Family values are more important to us than money".

It is apparent that Indigenous students' work values are vastly different from the capitalist masculine outcome expectations of accounting, in a way that drive them away from majoring in accounting and have them focus more on careers in education, medicine, and art in which they see a closer connection to their community and land.

"I want to major in something that helps me to help the people in my community"

"I want to become a police officer"

"I want to become a school teacher in the community so that not many students get to leave their communities to continue their studies at boarding schools"

"I want to start a senior school so that students have the option to study in their communities"

"I want to become an artist to reflect my culture"

A participant, who like most participants faced difficulties acquiring education, was willing to become a teacher in order to help others. She stated that: 'I wanted to become a teacher mainly to help students and little kids learn ... I would have done that to all students, not only Indigenous students, they are all kids and need the education.' 
Another student who is studying law, is no different to the other participants. She is doing it to benefit her community. She stated:

'I suppose I see it as a tool that I can use to help Indigenous people ... maybe bridge that gap in the law where ... a lot of people who are Indigenous, especially out in the communities, see it as, that's the White law. And I want to ... bridge that gap and help them understand this is the law, everyone follows it and just, sort of, help them to understand that's what it is. Because there are a lot of Indigenous people, especially out in the communities; they don't understand it and then when they do something wrong it's not explained to them. They don't understand that there are a set of rules ... I just think that going into, or studying law, I can get as much knowledge as I can possibly then help translate it back to them, to get an understanding so that they can actually be a part of society productively ... so just, sort of, help them out instead of getting the arse- end of the law when they get told, you've done something wrong, you're going to get locked up for it, or here's a fine. And then they're still sitting there like, I don't understand what I've done. So I guess that's, kind of, maybe my wanting.'

The following quotations illustrate that a major influence behind participants' decisions to study a particular course is the ability to help their communities.

'I just suppose they need a lot of Aboriginal teachers, for the Aboriginal kids. And, like, I can relate to them, and, yes. I can, like, be a role model for them and help them go through school, yes, the way I went through school. Because I never really had, like, Aboriginal teachers or role models, and I want to be that for the other, for the younger mob. I can see myself making a difference with this degree... .'

Others' interest in taking degrees in social work have mainly been driven by a desire to help people who have been stolen from their families.

'I want to be a social worker, so I can help people (Aboriginal people and nonAboriginal people) that have been taken away from their families, because I have been taken away from my family. I know my family now, but when I was a kid, I did not. Because I have experienced it, I would like to help other kids that are going through it, so I can tell them that I have been through it ever since I was little kid baby. I'd just like to do that.'

Another student, who is more interested in biomolecular science than marine biology, decided to study marine biology instead because he sees greater benefits to his community with such a course.

'I wanna help my community ... I am from the islands so like help out my own where I am from. And there is a lot of research that I can help with. Like if I am the marine biologist with the group, I can talk to the people, where I can be a bridge between the Islanders and whites. We are very connected to the ocean. In the past people used to catch a type of shell and traded it with Fiji and other countries for wheat and stuff like that, but now the whites are taking full control, they hire the islanders to do most of the work, and they just pay them wages. I just wanna be like a bridge, like if there is something that I understand I can explain it to them in our language, and they can understand me, and like they might be more comfortable talking to me instead of a white person. 


\section{CONCLUSION}

This study showed that the reasons Indigenous students avoid accounting specialization are culturally developed and defined. It is clear that there has been a dichotomy between the Indigenous Australians' cultural and social values and the current western-capitalist accounting values. Previous studies show that students who choose accounting perceive it as a career that provides them with material success, wealth, ambition, and individual independence. These accounting career's work values contradict the Indigenous students' expected work values that have been developed within the notions of their feminine cultural identity. The Indigenous culture has been more concerned with human capital, kinship, nurturing, caring, sharing, community affection, and belonging to the land rather than with material possessions, ownership, individual control, and other mainstream capitalistic values of individual wealth.

The study explained that Indigenous rituals, norms and cultural values, in addition to some other factors, have contributed to the lack of educational efficacy that students perceive necessary to follow an accounting major. The literacy and numeracy levels in Indigenous communities have not been at the level that makes accounting a study that is grasped easily. Many of the accounting quantitative measures and linguistic terms do not have a meaning in the Indigenous society and some of them even have a contradictory meaning such as the concept of ownership that does not exist in their culture.

It has been concluded from the study that a 'pull back' to the community has existed between all Indigenous students. They all wanted to specialize in areas that are useful to the community and keeps them participating such as arts, medicine, and teaching. This also shows that accounting is not perceived by students to be relevant and useful to the community. However, the recent and growing awareness among Indigenous leaders that accounting is useful for selfdetermination and for administering community wealth proves the necessity of spreading that awareness between the different social groups of the community to increase the number of Indigenous students studying accounting. This at the same time requires a considerable investment in social welfare to reform the disadvantaged socio-economic environment of the Indigenous communities, in a way that the necessary educational infrastructure will be protected and respected within the Indigenous cultural identity.

\section{References}

Australian Bureau of Statistics, ABS homepage [Internet documents] [created 2006; cited 12 ${ }^{\text {th }}$ August 2010], available from

http://www.abs.gov.au/websitedbs/cashome.nsf/4a256353001af3ed4b2562bb00121564/be2634628102566bc a25758b00116c3d!OpenDocument

Adams, S. J., L. Pryor, and S. L. Adams, 1994, Attraction and retention of high-aptitude students in accounting: an exploratory longitudinal study, Issues in Accounting Education, 9(1), 45-58.

Ahmed, K., K. F. Alam, and M. Alam, 1997, An empirical study of factors affecting accounting students' career choice in New Zealand, Accounting Education: an international journal, 6(4), 325-335.

Ajzen, I., 1988, Attitudes, Personality and Behaviour (The Dorsey Press, Chicago, IL).

Ajzen, I. and T. J. Madden, 1986, Prediction of goal-directed behaviour: Attitudes, intentions, and perceived behavioural control. Journal of Experimental Social Psychology, 22, 45-74.

Albrecht W, S., and J. R. Sack, 2000, Accounting Education: Charting the Course through a Perilous Future, Accounting Education Series, 16.

Auyeung, P. and J. Sands, 1997. Factors influencing accounting students' career choice; a cross cultural validation study, Accounting Education: an international journal, 6(1), 13-23.

Bell, H., 1986, White teacher, black learner: the influence of the cross-cultural context on teaching practice, Australian Journal of Adult Education, 26(3), 29-32. 
Berndt, R.M. and C. H. Berndt, 1988, the World of the First Australians Aboriginal Traditional Life: Past and Present, (Aboriginal Studies Press, Canberra).

Birrell, B., D. Edwards, I. Dobson, and F. Smith, 2005, the myth of too many university students, People and Place, 13(1), 63-70.

Blake, B.J., 1981, Australian Aboriginal languages, (Angus and Robertson, Sydney).

Booth, P. and H. Winzar, 1993, Personality biases of accounting students: some implications for learning style preferences, Accounting and Finance, November, 109-120.

Boughen, P.D., 1994, Joking apart: The serious side to the accountant stereotype, Accounting Organizations and Society, 319-335.

Brandenstein, V., 1970, What Next in Aboriginal Australian Linguistics? The Etruscan, 19(2), 11-15.

Brown, D., 1996, Brown's values-based, holistic model of career and life-role choices and satisfaction, in: D. Brown \& L. Brooks and Associates, eds, Career choice and development (Jossey-Bass, San Francisco) 337-372.

Brown, D., 2002, The role of work and cultural values in occupational choice, satisfaction, and success: a theoretical statement, Journal of Counseling and Development, 80 (1), 48-56.

Cangelosi, R. J., F. A. Condie, and D. H. Luthy, 1985, the influence of introductory accounting courses on career choices, Delta Phi Epsilon Journal, 27(1), 60-68.

Chambers, R.J., 1991, Foundations of Accounting, (Deakin University Press, Australia).

Cohen, J. and D. Hanno, 1993, an analysis of the underlying constructs affecting the choice of accounting as a major, Issues in Accounting Education 8(2), 219-238.

Cohen, P. and M., Somerville, 1990, Ingelba and the Five Black Matriarchs, (Allen \& Unwin, Australia, Sydney).

Commonwealth Department of Education, Training and Youth Affairs, DETY Home page [Internet document], (Australia) [created 2000, cited August 2009], available from http://www.dest.gov.au/archive/publications/annual_reports/2000/html/chapter_3.htm\#2_1

Department of Education and Training, DET Home page [Internet document], (Department of Education and Training, Western Australia) [created 2006, cited August 2009], available from http://www.det.wa.edu.au/education/abled/apac/lessons/pdfs/apac024.pdf

Dingle, T,1988, Aboriginal Economy (McPhee Gribble/Penguin Books, Ringwood).

Eades, D. 1988, They don't speak an Aboriginal language, or do they?, in: I. Keen, ed, Being Black: Aboriginal "cultures" in settled Australia (Aboriginal Studies Press, Canberra) 97-115.

Elkin, A.P, 1981, The Australian Aborigines (Angus \& Robertson, Sydney).

Felton, S., N, Buhr, and M, Northey, 1994, Factors influencing the business student's choice of a career in chartered accountancy, Issues in Accounting Education, 9(1), 131-141.

Fishbein, M. and I, Ajzen, 1975, Belief, Attitude, Intention and Behaviour: An Introduction to Theory and Research (Reading, MA: Addison-Wesley).

Gaffney, M. A., R. A, McEwen, and M. J, Welsh, 1995, Expectations of professional success in accounting: An examination of race and gender differences, Advances in Public Interest Accounting, 6, 177-202.

Gainor, K. A., and R. W, Lent, 1998, Social cognitive expectations and racial identity attitudes in predicting the math choice intentions of Black college students, Journal of Counseling Psychology, 45, 403-413

Garner, R. M., and R. F. Dombrowski, 1997, Recruiting the 'Best and the Brightest': The Role of University Accounting Programs and State CPA Societies, Issues in Accounting Education, 12(2), 299-314.

Gecas, V., and M. L. Schwalbe, 1983, beyond the looking-glass self: Social structure and efficacy-based self-esteem, Social Psychology Quarterly, 46, 77-88.

Geiger, M. A., and S. M. Ogilby, 2000, the first course in accounting: students' perceptions and their effect on the decision to major in accounting, Journal of Accounting Education, 18(2), 63-78.

Gibson, K., 2000, Accounting as a tool for Aboriginal dispossession: then and now, Accounting, Auditing \& Accountability Journal, 13(3), 291.

Godfrey, J., G. Partington, M. Harslett, and K. Richer, 2001, Attitudes of Aboriginal Students to schooling, Australian Journal of Teacher Education, 26 (1). 
Grace, D. M. and J. W., Gilsdorf, 2004, Classroom Strategies for Improving Students' Oral Communication Skills, Journal of Accounting Education, 22, 165-172.

Greer, S. and C. Patel, 2000, The issue of Australian indigenous world-views and accounting.' Accounting, Auditing and Accountability Journal, 13 (3), 307-329.

Gul, F. A., 1986, Adaption - innovation as a factor in Australian accounting undergraduates' subject interests and career preferences, Journal of Accounting Education, 4(1), 203-209.

Gul, F.A., B. H, Andrew, S. C. Leong, and Z, Ismail, 1989, Factors influencing choice of discipline of studyaccountancy, engineering, law and medicine, Accounting and Finance, 29 (2), 93-101.

Haddon, A.C., 1890, the ethnography of the western tribes of Torres Straits, Journal of the Anthropological institute of Great Britain and Ireland, 19, 297-437.

Hardin, R. J., D. O’Brian, and J, Quirin, 2000, Accounting Versus Engineering, Law, and Medicine: Perceptions of Influential High School Teachers, Advances in Accounting, 17, 205-220.

Harris, J., 1987, Australian Aboriginal and Islander Mathematics, Australian Aboriginal Studies, 2, 29-37.

Harris, P., 1991, Mathematics in a Cultural Context: Aboriginal Perspectives on Space, Time and Money (Deakin University Press, Melbourne).

Harris, S., 2000, Two-Way Aboriginal Schooling: Education and Cultural Survival (Aboriginal Studies Press, Canberra).

Helme, S., 2005, Indigenous students and Vocational Education and Training in Schools: Ladder of opportunity or corrugated iron ceiling?, Australian Journal of Education, 49 (2), 169-181

Helme, S., and S. Lamb, 2011. Closing the school completion gap for Indigenous students (Closing the Gap Clearinghouse, Australia).

Hermanson, D. R. and R. H, Hermanson, 1995, Are America's top businesses students steering clear of accounting?, Ohio CPA Journal, 54(2), 26-30.

Hines, R. D., 1992, Accounting: Filling the Negative Space, Accounting, Organizations and Society, 17, 313-342.

Hofstede, G., 1980, Culture's Consequences: International Differences in Work-related Values (Sage, Beverly Hills, CA).

Hofstede, G., 1983, the cultural relativity of organizational practices and theories, Journal of Business Studies, Fall, 75-90.

Horowitz, K. and T. Riley, 1990, How do students see us?, The Human Resource, 106, 75-77.

Hughes, M., and D. H. Demo, 1989, Self-perceptions of Black Americans: Self-esteem and personal efficacy, The American Journal of Sociology, 95, 132-159.

Hunter, B. H., 2010. Pathways for Indigenous school leavers to undertake training or gain employment (Closing the Gap Clearinghouse, Australia).

Inman, B. C., A, Wenzler, and P. D. Wickert, 1989, Square Pegs in Round Holes: Are Accounting Students WellSuited to Today's Accounting Profession? Issues in Accounting Education, 4(1), 29-47.

Jackling, B. and C. Calero, 2006, Influences on Undergraduate Students' Intentions to become Qualified Accountants: Evidence from Australia, Accounting Education: an International Journal, 15 (4), 419-438.

James, K., 2008, Barriers to recruiting African-American students into accounting, Research in Higher Education, 1, 45-51.

Keeffe, K., 1992, From the Centre to the City: Aboriginal Education, Culture and Power (Aboriginal Studies Press, Canberra).

Lancaster University, LUMS Home page [Internet documents] (United Kingdom) [created 2009, cited August 2009], available from: http://www.lums.lancs.ac.uk/departments/Accounting/undergraduate/whyaccfin/.

Lent, R. W., S. D. Brown, and H. Sheu, 2005, Social Cognitive Predictors of Academic Interests and Goals in Engineering: Utility for Women and Students at Historically Black Universities, Journal of Counselling Psychology, 52(1), 84-92.

Lippman, W., 1992, Public opinion, (Harcourt Brace, New York)

Lombardi, L. and B. M. Clayton, 2006, Indigenous Australian Accountants: Why so few? A Historical and Cultural 
Perspective, Global Business \& Economics Anthology, 1(1), 63-74.

Lombardi, L. and B. M. Clayton, 2009, The Path Less Travelled: Indigenous Australians and the Accounting Profession, Paper presented at the Interdisciplinary Perspectives on Accounting Conference, Innsbruck, Austria.

Lovesy, H. and C. Fraser, 1999, The Money Story, Paper presented at the Community Conference, Alice Springs.

Lowe, D. R., and K. Simons, 1997, Factors influencing choice of business majors - some additional evidence: a research note, Accounting Education: an international journal, 6(1), 39-45.

Mauldin, S., J. L. Crain, and P. H. Mounce, 2000, The accounting principles instructor's influence on students' decision to major in accounting, Journal of Education for Business, 75(3), 142-148.

Maybury-Lewis, D., 1992, Millennium: Tribal Wisdom in a Modern World, (Viking Penguin, NY)

McMillan, J. and J. Western, 2000, Measurement of the socio-economic status of Australian higher education students, Higher Education, 39(2), 223-248.

Mladenovic, R., 2000, an investigation into the ways of challenging introductory accounting students' attitudes towards accounting as a profession, Accounting Education: an International Journal, 12(2), 113-133.

Myers, F.R., 1976, to have and to hold: a study of persistence and change in Pintupi social life, PhD thesis (Bryn Mawr College, Bryn Mawr, US).

Paolillo, J. G. P. and R. W, Estes, 1982, An empirical analysis of career choice factors among accountants, attorneys, engineers and physicians, The Accounting Review, LVII(4), 785-793.

Parker, L. D., 2000, Goodbye, number cruncher, Australian CPA, 70(2), 50-52.

Parker, L.D., 2001, back to the future: the broadening accounting trajectory, British Accounting Review 57(4), 78593.

Peterson, N. and M, Langton, 1983, Aborigines, Land and Land Rights (Australian Institute of

Aboriginal Studies, Canberra).

Povinelli, E.A., 1993, Labor's Lot: The Power, History, and Culture of Aboriginal Action, (The University of Chicago Press, Chicago).

Purdie, N., and S. Buckley, 2010, School attendance and retention of Indigenous Australian Students (Closing the Gap Clearinghouse, Australia).

Reid, K., 2008, the causes of non-attendance: an empirical study, Educational Review, 60, 345-57.

Roe, R. A., and P. Ester, P., 1999, Values and work: Empirical findings and theoretical perspective, Applied Psychology: an International Review, 48(1), 1-21.

Rose, M., 2012, Indigenous accountants in deficit, The Australian, January 11.

Sharp, N., 1996, No Ordinary Judgment: Mabo, the Murray Islanders' Land Case (Aboriginal Studies Press, Canberra).

Sherman, W. R. and W. G. Jr. Tymon, 1997, Empowering accountants, National Public Accountant, March/April: 4043.

Simpson, J. C., 2001, Segregated by Subject: Racial differences in the factors influencing academic major between European Americans, Asian Americans, and African, Hispanic, and Native Americans, Journal of Higher Education, (January), 63.

Smith, G., 2005, Reversing the Decreasing Trend of Students Majoring in Accounting, Managerial Auditing Journal, 20(9).

Tindale, N.B., 1925, Natives of Groote Eylandt and of the West Coast of the Gulf of Carpentaria, Records of the South Australian Museum, 3, 61-134.

Wallace, W. A., 1997, Where are the debits and credits? Editor's perspective. Issues in Accounting Education, 12 (1), 229-230.

Watson, P., G. Partington, J. Gray, and L. Mack, 2006, Aboriginal Students and Numeracy (Edith Cowan, Perth).

Witherspoon, K. M., and S. L. Speight, 2009, an exploration of African Americans' interests and self-efficacy beliefs in traditional and non-traditional careers, Journal of Black Studies, 39(6), 888-904. 
Wolk, C. M. and T. A. Cates, 1994, Problem-solving styles of accounting students: are expectations of innovation reasonable?, Journal of Accounting Education, 12(4), 269-281.

Wong, D. S. N., and Y. Chia, 1996, English language, mathematics and first-year financial accounting performance: a research note, Accounting Education, 5 (2), 183-189.

Zeff, S. A., 1989, Does accounting belong in the university curriculum?, Issues in Accounting Education, 4(1), 203210 . 